Original Research Paper

\title{
Examination of Preservation, Maintenance and Prevention from Corrosion in Water Cylinders
}

\author{
${ }^{1}$ Kaveh Ostad-Ali-Askari, ${ }^{2}$ Vijay P. Singh, ${ }^{3}$ Nicolas R. Dalezios, \\ ${ }^{4}$ Theodore C. Crusberg, ${ }^{1}$ Hossein Gholami and ${ }^{5}$ Mohsen Ghane \\ ${ }^{1}$ Department of Civil Engineering, Isfahan (Khorasgan) Branch, Islamic Azad University, Isfahan, Iran \\ ${ }^{2}$ Department of Biological and Agricultural Engineering and Zachry Department of Civil Engineering, \\ Texas A and M University, 321 Scoates Hall, 2117 TAMU, College Station, Texas 77843-2117, USA \\ ${ }^{3}$ Laboratory of Hydrology, Department of Civil Engineering, University of Thessaly, Volos, Greece and \\ Department of Natural Resources Development and Agricultural Engineering, \\ Agricultural University of Athens, Athens, Greece \\ ${ }^{4}$ Department of Biology and Biotechnology, Worcester Polytechnic Institute, Worcester, MA 01609-2280, USA \\ ${ }^{5}$ Department of Civil Engineering, South Tehran Branch, Islamic Azad University, Tehran, Iran
}

Article history

Received: 21-10-2018

Revised: $18-11-2018$

Accepted: 06-12-2018

Corresponding Author:

Kaveh Ostad-Ali-Askari

Department of Civil

Engineering, Isfahan

(Khorasgan) Branch, Islamic

Azad University, Isfahan, Iran

Emails: Kaveh.oaa2000@gmail.com koa.askari@khuisf.ac.ir

\begin{abstract}
Reduction of water constructions and installations problems, improvement of construction life, provision, transference, distribution, purification and reservation of water are of the most important matters in urban culture due to the importance of drinkable water supply for cities and villages of the country, considering the increase of need in consumption of water supply. One of the basic troubles of industries and consumers in the whole country is the maintenance of water infrastructure and constructions which cost a fortune to construct and utilize. Through the stage of utilization, preservation of the facility is very important. Through this presentation, we take a look at the subject of corrosion in Water cylinders made of metal, concrete or mixed materials considering past experience. Corrosion is mostly due to an unsuitable environment. Such soluble compounds as sulfur, hydrogen, carbon dioxide etc. in the water accelerates the process of corrosion greatly.
\end{abstract}

Keywords: Amelioration, Strengthening (Resentencing), Corrosion, Water Cylinder Corrosion

\section{Introduction}

Water supplies and their essentials are the key to development and human growth, however, natural disasters and damages due to unsuitable environment reduced utilization of the water supplies. Through this essay, we deliberate the corrosion dilemma and examine efficiency of the preservation procedures in hand based on Water Company experiences (Wu et al., 2017).

\section{Drinkable Water Cylinders}

Water Cylinders which are required to be designed and manufactured due to safety factors for different conditions are produced in different structures due to different applications. Through this study, corrosion in water cylinders made of metal, concrete or mixed materials which are used in the water industry of the country is explained. These water cylinders are made of either metal or non-metal (composite) materials or a mixture of both of which, designs are required to be produced requiring the least budget and material, manufacture of such cylinders include complex designs and production processes. Such cylinders must be persistent to static and dynamic charges, exhaustion in different environments and damages (Quevedo et al., 2018).

\section{All Metal Water Cylinders}

This kind of Steel, Aluminum or mixed concrete alloys water cylinders need to pass performance tests however the standards are not set for the type of the alloy and design tensions. These tests are necessary to ensure resistance to corrosion and exhaustion. The safety of the water cylinders is tested and observed by doing destructive and nondestructive experiments such as rigidity test, Hydrostatic pressure test, CrMo determination (HOOP Wrapped Cylinders Production Test Certificate).

\section{Hoop Wrapped Water cylinders}

These cylinders are made of Steel or Aluminum or mixed concrete which are strengthen in radius by composite material and ERP or two-layer Geo- 
membranes, Except for the two ends of the water cylinder which are usually made of glass, carbon or Armid fibers with Resin.

Composites employed in water cylinders are mostly Epoxy or Resin Iso-phthalic Polyester.

\section{Fully Wrapped Water Cylinders}

This type of water cylinders is made of Steel, Aluminum or Concrete mixtures strengthened by composite fibre on radius and axis. They are lighter than Hoop Wrapped and the two-direction strengthening by composite fibre has led this type to take more pressure and charge than Hoop Wrapped cylinders. Moreover, concrete mixture cylinder type is built more persistent due to consideration of different loading for it (ISO/FDIS 11439, 1999).

\section{All Composite Water Cylinders}

This type of Water Cylinders is again strengthened by composite fibre on radius and axis, but it's different in the material which linear wall is made from, which is Polyethylene. The Loading capacity of this type is proportional to its strengthening and it is more persistent to load and pressure in horizontal shape than metal, concrete and not strengthened (Cylinder Care and Maintenance Handbook).

\section{Ferroconcrete Cylinders}

This type of water cylinders is made of ferroconcrete. Life of this water cylinder is much more than other types and they work more applicable in southern parts of the country. However, they are not applicable in cold regions due to implementation problems.

\section{Stone Cylinders}

This type was formerly built in regions having no appropriate material, the stone in which the region of the building was rich, was convenient. Corrosion of this type highly depended on the kind quality of stone found in the area and materials used (Fukaya and Watanabe, 2018).

\section{Utilization Conditions of Water Cylinders}

Utilization conditions of water cylinders are different according to the region, weather conditions, water quality, the process of building, application situation and loading and unloading conditions (AWWA, 2003).

\section{Problems due to Water Quality}

Transferring and saving water or any other liquid depends on its quality and combination control. Generally, saving water won't face any problems as long as it runs in pipelines having specific combinations. Carbon dioxide, Oxygen and Sulfur (H2S) are ingredients responsible for corrosion of cylinders especially uncovered concrete type. Limitation is set about the amount of sulfide hydrogen, the more of this substance, the more corrosion. Effect of water quality and other characteristics are examined separately.

Water: when the wall of the cylinder is exposed to water, it faces problems unless the material is in the category not damaged by water.

Corrosion decreases in winter. Still, water in pipelines and cylinders increases the possibility of corrosion. Water may cause corrosion and producing base combinations.

Carbon dioxide: carbon dioxide in water increases corrosion in Steel and concrete cylinders.

The Pace of corrosion depends on pressure, temperature, the amount of iron carbonate, density and resistance of materials of which the cylinder is made. Corrosion may occur in places where the water is being still and upper parts are safe, however, sometimes corrosion in upper parts is more due to brume or even air.

Hydrated combinations: as the pressure increases in the cylinder, hydrated combinations are produced at above a temperature of $0 \mathrm{C}$ (meaning this happens less in cold regions). This could lead to blockage of pipes, valves, pressure regulators, evacuation pool, fire valves and safety valves. Therefore, a specific range for the amount of water is defined for each cylinder. The density of corrosive combinations in water must be as low as to keep the freezing point of the water in the cylinder lower than the least freezing point of water in the environment at a pressure of 5 centigrade. Practically this means 10 to 50 milligrams per cubic meter (Sean Brossia, 2018).

Hydrogen Sulfide: hydrogen sulfide dissolved in water makes an acidic combination and increases corrosion and frangibility of metal. Experiments suggest that intensity of corrosion depends on the amount of hydrogen in the environment.

Sulfur: due to low dissolvability in water, sulfur doesn't cause corrosion much.

Mercaptan: This redolent substance, dissolves at the low amount in water, therefore it doesn't cause corrosion (Deyab, 2018).

\section{Corrosion}

Corrosion is one of the most important matters in engineering science that causes many economic, environmental, technical, safety and etc. problems as well as having a noticeable the number of industrial studies and projects. Rise of energy supply cost, human resources, high temperature and pressure and more corrosive and complicated environments in industrial processes led to a progressive increase in economic loss through recent years. Importance of corrosion rises highly when it threatens users' safety directly through its influences. In service structures such as transferring lines and water cylinders, corrosion leads to utilization life decline and charging high costs (Nevshupa et al., 2018). 


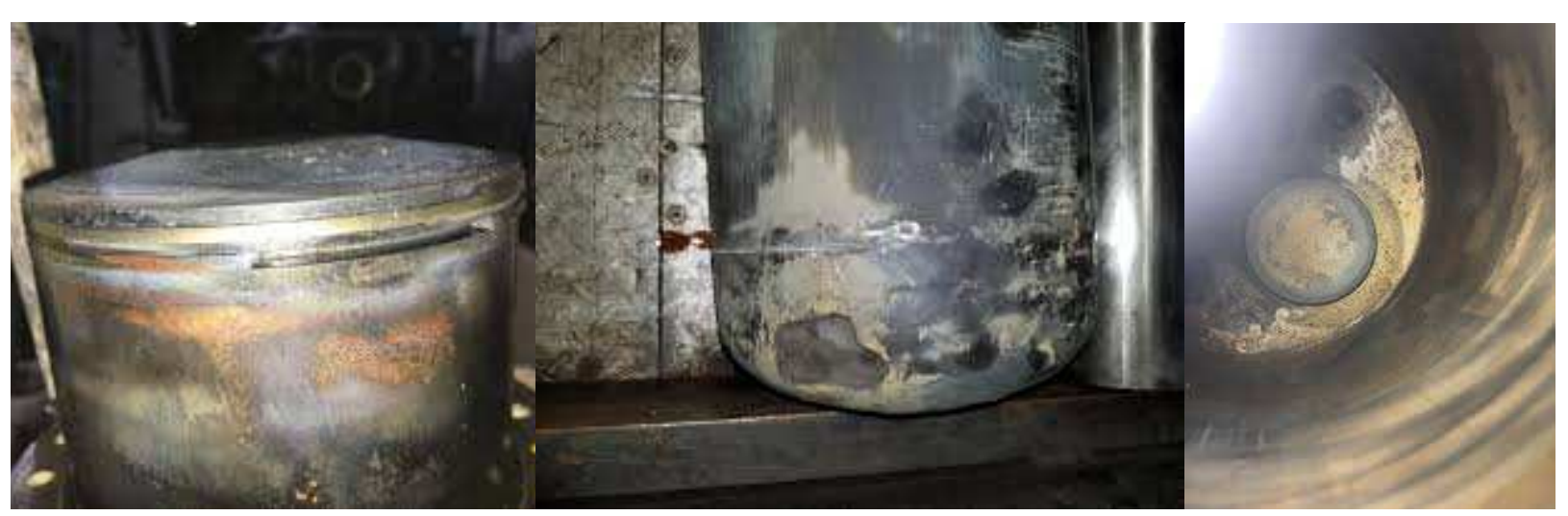

Fig. 1: Corrosion in Cylinders

The corrosion rate, the corrosion potential and the chloride content approximately the reinforcing cylinders were observed as a function of the exposure time, to acquire information about the corrosion kinetics. cylinders are often needed to represent better efficiency in wear and corrosion behaviour than the material the workpiece is made of can offer. The obstacle can be dominating when a protective coating is consigned into the inner walls (Fig. 1).

\section{Crevice Corrosion}

The most common corrosion in water cylinders is crevice corrosion. This happens in gaps and crevices in cylinders where corrosive solute stayed long. Crevice corrosion starts where the rubber meets metal. No gasket must be placed between holding belts and cylinder where liquid stays (Negm et al., 2018).

\section{Pitting}

Pitting happens when a small piece of the metal surface is exposed to the corrosive environment due to specific fault such as covering failure and it is corroded intensely. This corrosion is highly focused which leads to a hole in metal or composite.

Holes usually advance in the direction of gravity. Piercing is done through an and autocatalytic reaction. Cylinders used must be preserved from corrosive factors which are done by appropriate covering (twolayer Resin or Zeolite covering combined with sea cement) (Liang et al., 2018).

\section{Intergranular Corrosion}

Grain boundaries are energetic areas and they are more active chemically. That is why, when the surface of a metal or combined material is exposed to the corrosive material, grain boundaries get corroded faster than grain surface. It includes an inner rotating cylinder and an outer stationary cylinder. It rushes the inner cylinder than the outer owing to centrifugal forces. corrosion rates were defined by electrochemical evaluations. The consequences display that the corrosion properties of the coatings strongly affect the material loss rate (Fig. 2).

As you know, alloys are of two categories, heterogeneous and homogeneous, homogeneous alloys are more resistant to corrosion since there is no galvanic matter in them. Therefore, in order to produce a homogeneous alloy through stages of cylinder building, elements of which this solid solute is made must be observed.

Since Steel alloys are used as a material in building water cylinders, in the following an explanation of this resistance mechanism to corrosion of these types of Steel alloys is provided. Chromium $(\mathrm{Cr})$ plays the role of a victim to protect iron from corrosion as a basic base metal. When oxygen rushes to the metal surface, a great amount of iron oxide is made, but since Chromium combines with oxygen more than iron, iron oxide is remotely replaced by chromium oxide so, a sticky layer of chromium on the surface, makes a resistant layer and blocks infiltration of oxygen to the surface of iron oxide and thereby protects the metal. It shows the relationship between $\mathrm{pH}$, chloride condensation and oxygen condensation displays that a drying cycle, which locally concentrates chloride and oxygen, begins the corrosion of steel. Oxygen controls the rate of corrosion, but chloride influences the number of sites where corrosion launches (Fig. 3).

\section{Galvanic or Two Metal Corrosion}

The difference in electrical potential between two diverse metals which meet each other in spots leads to electron flow between them and leads to galvanic corrosion. Environment factors such as temperature, humidity and effect of the surface, the proportion of anode surface to cathode surface effect the pace of corrosion highly. Residual stresses straight affect the deformation of workpieces, their static and dynamic resistance and their chemical and electrical characteristics (Fig. 4). 

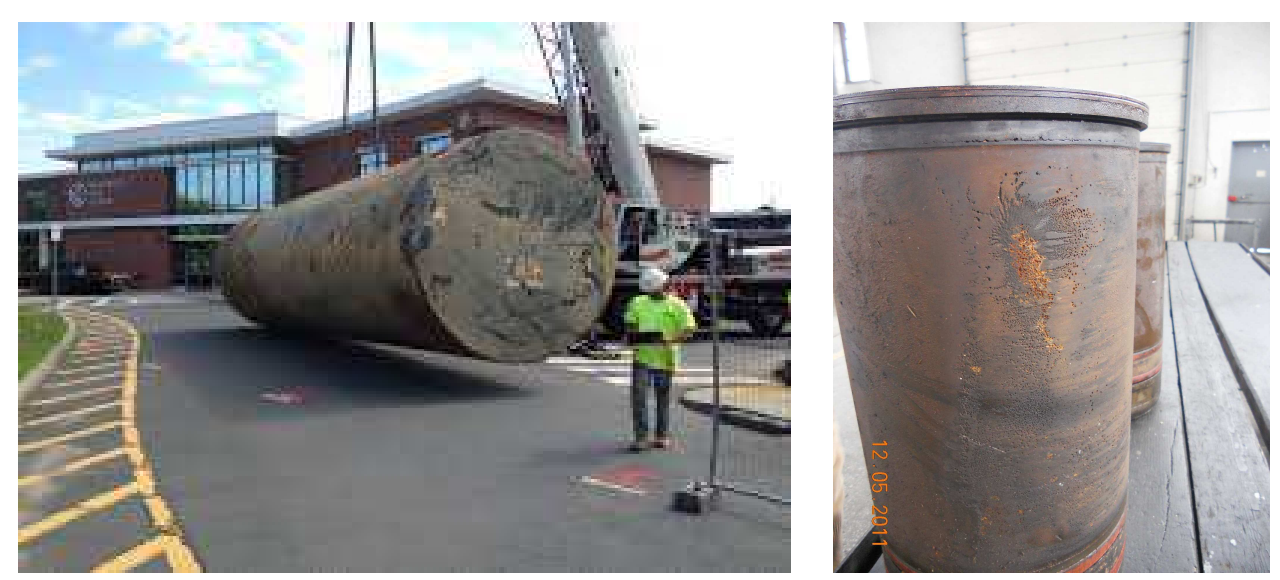

Fig. 2: High Corrosion in water cylinders

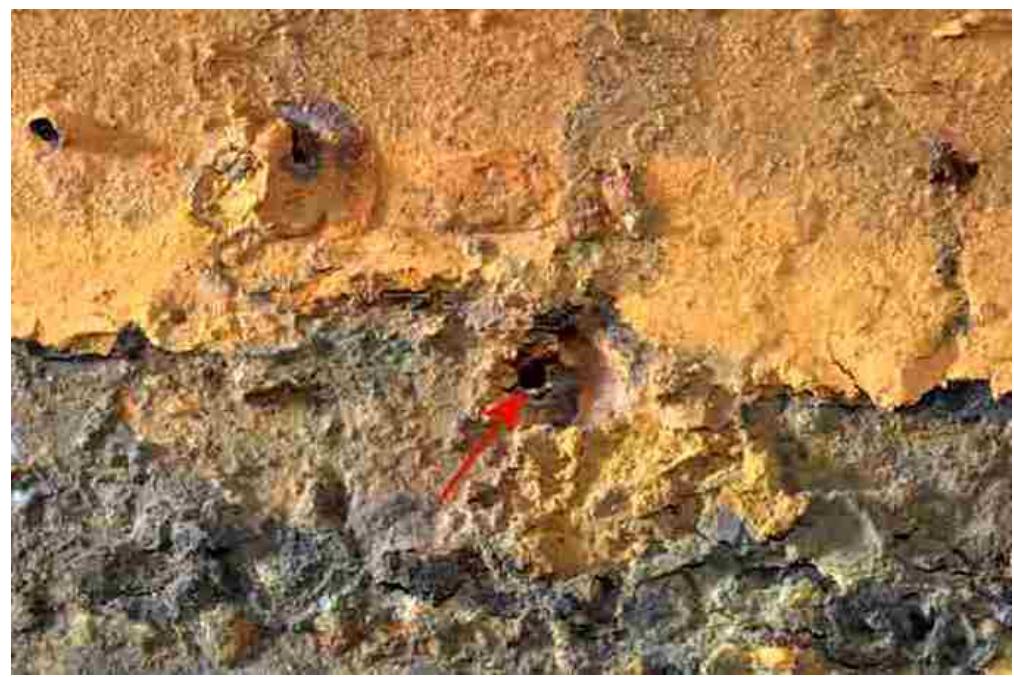

Fig. 3: High Corrosion in Steel portable water cylinder

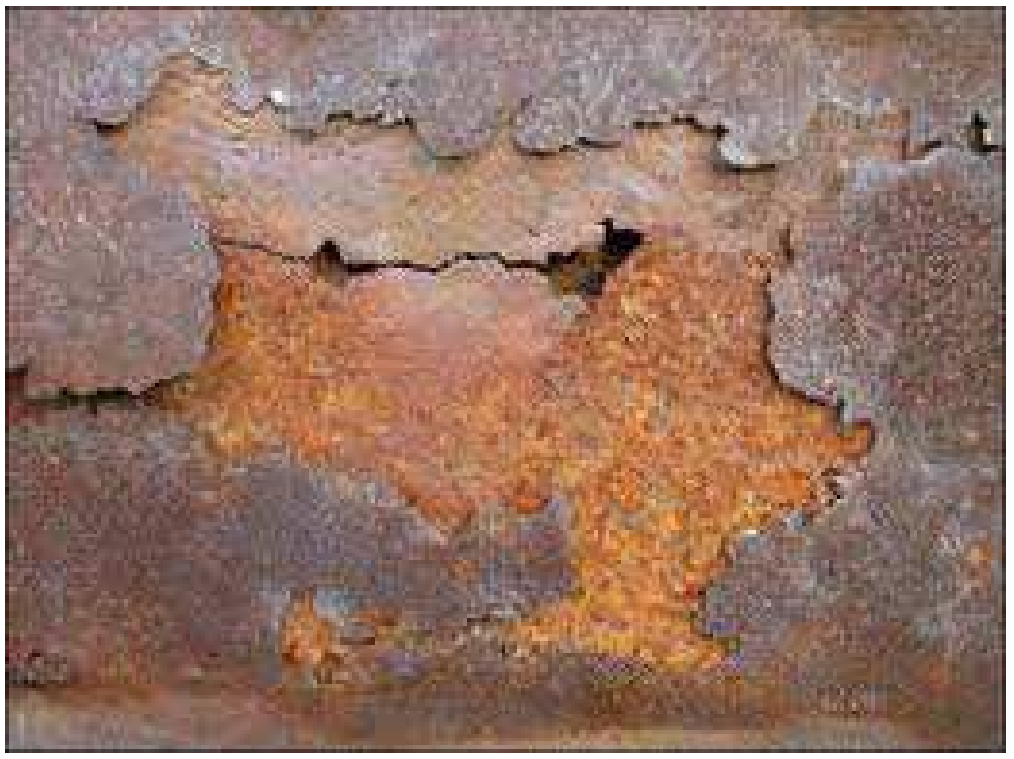

Fig. 4: Spot destruction of inside of the cylinder body due to corrosion 


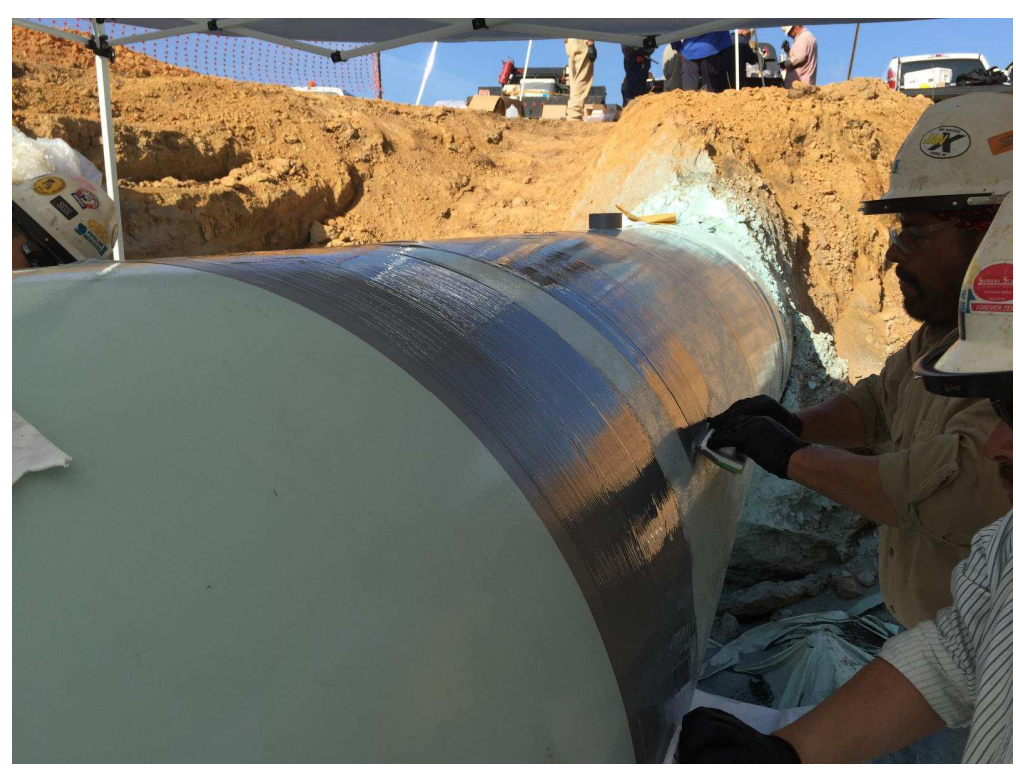

Fig. 5: Protection from corrosion by choosing the right material

Metal water cylinder meeting aluminium get corroded less and their lifetime increases by the protection of Steel body. This policy also works in concrete cylinders. The Material used is to be considered when choosing connectors and parts. Through connecting, it's suggested to use rubber and polyethylene material instead of gaskets and other metal things in order to reduce corrosion (Liu et al., 2018). increasing their mechanical properties and to ameliorate the surface finish, wear and corrosion resistance; thermally sprayed coatings can be applied. The quality of the coating belongs to the coating material, the chosen procedure, the preparation of the surface and spraying parameters (Fig. 5).

\section{SCC: (Stress Corrosion)}

This is a result of tensile stresses, the chemical combination of the solute, SCC of the corrosive environment on metal simultaneously. Stress and structure of the metal are important factors in chemical combination of metal or composite. For instance, these stresses may cause compression on one spot and lack of compression on another spot. This leads to a gap and in that gap, less compressed spots act as an appropriate anode for a corrosion by the environment. While, in compressed spots which act as the cathode, cannot be protected by acidic rain, since acidic rain is not strong enough for an SCC process (Gan et al., 2017).

\section{Solution}

Cylinders covered with glass fibres must not be touching acid. Batteries must not be near cylinders. These batteries can easily be leaned and sulfuric acid spills from them. Moreover, batteries give out sulfuric acid gas which sits on cylinders. Make sure that the batteries of the vehicle are in a safe distance from composite cylinders covered with glass fibres.

\section{Ready-to-Use Cylinders and Their Applications}

Considering natural water crisis in the country, lack of equality in raining, drought, reduction of water resources, population and usage growth, progress in industry and agriculture, which require great amount of good quality water, great deal of programming and planning, basic managing to decrease over usage and its damages and attending the subject of saving water is highly and definitely needed.

Ready-to-use cylinders' characteristics. This type of cylinders has many advantages rather than regular cylinders:

- They can be preserved to corrosion no matter what the material it is made of

- Resistant to environmental effects

- They can be screwed together and be built, taken apart and moved easily

- Perfect design and mechanical stability, under ISO license

- Provided at volumes of 25 to 1775 cubic meters and can be installed in the shortest time by least number of workers

- 90 to 95 percent prevention from water evaporation and algae growth, dust and insect proof due to air float floating sheets or Gena-roof or air top Sil-aroof

- High tensile strength

- High resistance to length changes due to heat 
- Resistant to strong wind

- Resistant to artificial aeration in sewage filtration, Pisciculture and shrimp farming

- Filling up least space for saving different volumes of water, even for indoor spaces

- Quantity and quality of water inside these cylinders are easily measurable and controllable even on an everyday basis

- For high corrosion regions, the sheets of the cylinder are coated from both sides, so they work at regions with high corrosion even for salt marsh, for 30 years

- Different types of Aquatic covering are specially designed for different climates, from cold to hot regions, for high UV degrees and also different applications such as industrial, agricultural, farming etc

- Ready-to-use Water cylinders' applications

- Under international licenses of ISO 9001, KIWA, ATA, totally appropriate for saving drinkable water

- Appropriate for saving different industrial fluids totally safely in order to prevent from leaking and therefore saves the environment

- Appropriate for Pisciculture and shrimp farming

- Appropriate for saving rainwater and other kinds to use in agriculture, farming and watershed management in different regions of the country

- For saving water in parks, sports fields and urban squares

- $\quad$ For temporary saving oil

- User groups: structure, industry, environment etc.

Disadvantages of concrete cylinders rather than ready-to-use cylinders:

1- Concrete cylinders are much more expensive than galvanized ready-to-use cylinders

2- Installation of concrete cylinders requires a great period of time and utilization cannot occur right after the building is done since concrete needs time to get stable, while ready-to-use cylinders don't

3- Ready-to-use cylinders are flexible since they can be taken apart, moved and attached but concrete cylinders can't

4- Concrete cylinder requires a stronger foundation than galvanized cylinders

5- Due to the production of hydrogen sulfide in urban sewage which corrodes concrete, it cannot be used for this application

1- Concrete cylinders, unlike ready-to-use cylinders, have limitations in time and place of building and installation

2- Even though concrete is a common material used in structures, it has disadvantages such as low tensile strength and plasticity, low energy absorption, contraction and shrinkage and after that cracking because of it and also, cracking due to wrong producing and hardening of concrete (Yeom et al., 2018)

In the argument of these consequences, a new instrument for trans granular pressure corrosion is offered. When instances were distorted within the corrosive surroundings, the tubal rush and the external roughening were perceived to be intensified in the areas of serious deformation. perceptions also demonstrated that for all the alloys checked, static displacements did not begin chemical offence. It is suggested that when sensitive alloys are subjected to stress corrosion cracking circumferences a mechanically feeble, pitted construction is built along active slip cylinders and that directorial fracture happens through this rusty substance. The chemical activity of the lapse cylinders, which are trusted to begin the pitting attack, is argued in relation to the kind of surface slip structure found in alloys. The attendance of these accelerates was related with the trans- granular stress corrosion capacity of these alloys. The feasibilities porous metallic structures are survived. Non-disastrous, as well as disastrous procedures, are explained. Results of the disclosure on the FRP composite and its components, as well as interplay effects, develop from FRP composite-concrete bond are explicated and failure mechanisms are précised. It is exhibited that the detriment mechanisms seen are those that would get bigger sorption of water in instances where aqueous dilutions may be offered. concepts on the overall operation are considered (Tang et al., 2018).

\section{Conclusion}

The most significant subjects in town civilization because of significance of potable water reserve for towns and small towns of the nation, taking into account the expansion in require of squandering of water stock which are the decrease of water buildings and installations obstacles, recovery of building existence, preparation, conduction, dispensation, refinement and supply of water. In this article, we consider the matter of corrosion in water cylinder is produced by the metal, concrete, mixed substances inspecting past trial. Corrosion is often because of the improper surroundings.

One of the most controversial issues in the evaluation of cylinders is different kinds of corrosions in it and the ways to fight them. This essay, after examination of different kinds of corrosion in order to prevent from this unwanted phenomenon, suggests that cylinders covered with glass fibres must not be exposed to acidic substances and combinations.

Different experiments such as acidic environment experiment, cylinder under salty water conditions experiment are set, however, most of them are presented by other ISO valid standards based on 11439. Evaluating experiments showed that ready-to-use cylinders must pass specific conditions versus regularly pressured cylinders. 


\section{Acknowledgement}

This research was supported the Isfahan University of the Technology. We thank our colleagues from different universities who provided insight and expertise that greatly assisted the research.

\section{Author's Contributions}

All authors contributed to design the study, write and revise the manuscript.

\section{Ethics}

The present Study and ethical aspect were approved by the Isfahan University of the Technology.

\section{References}

AWWA, 2003. Handbook of water storage.

Deyab, M.A., 2018. Efficiency of cationic surfactant as microbial corrosion inhibitor for carbon steel in oilfield saline water. J. Molecular Liquids, 255: 550-555.

Fukaya, Y. and Y. Watanabe, 2018. Characterization and prediction of carbon steel corrosion in diluted seawater containing pentaborate. J. Nuclear Mater., 498: 159-168.

Gan, Y.X., J. Dong and J.B. Gan, 2017. Carbon network/aluminum composite made by powder metallurgy and its corrosion behavior in seawater. Materials Chemistry Physics, 202: 190-196.

ISO/FDIS 11439, 1999. Gas cylinder-high pressure1 cylinder for the on-board storage of natural gas as a fuel for automotive vehicles.

Liang, M., R. Melchers and I. Chaves, 2018. Corrosion and pitting of 6060 series aluminum after 2 years exposure in seawater splash, tidal and immersion zones. Corrosion Science.
Liu, H., X. Zhong, H. Liu and Y.F. Cheng, 2018. Microbiologically-enhanced galvanic corrosion of the steel beneath a deposit in simulated oilfield-produced water containing Desulfotomaculum Nigrificans. Electrochemistry Communications, 90: 1-5.

Negm, N.A., M.A. Migahed, R.K. Farag, A.A. Fadda and M.M. Shaban, 2018. High performance corrosion inhibition of novel tricationic surfactants on carbon steel in formation water: Electrochemical and computational evaluations. J. Molecular Liquids, 262: 363-375.

Nevshupa, R., I. Martinez, S. Ramos and A. Arredondo, 2018. The effect of environmental variables on early corrosion of high-strength low-alloy mooring steel immersed in seawater. Marine Structures, 60: 226-240.

Quevedo, M.C., G. Galicia, R. Mayen-Mondragon and J.G. Llongueras, 2018. Role of turbulent flow seawater in the corrosion enhancement of an $\mathrm{Al}$ $\mathrm{Zn}-\mathrm{Mg}$ alloy: An Electrochemical Impedance Spectroscopy (EIS) analysis of Oxygen Reduction Reaction (ORR). Technology, 7: 149-157.

Sean Brossia, 2018. Chapter 23: Corrosion of pipes in drinking water systems. Handbook of Environmental Degradation of Materials, pp: 489-505.

Tang, F., Y. Chen, Z. Li, Y. Tang and G. Chen, 2018. Application of Fe-C coated LPFG sensor for early stage corrosion monitoring of steel bar in RC structures. Construct. Build. Mater., 175: 14-25.

Wu, J., P. Wang, J. Gao, F. Tan and S. Chen, 2017. Comparison of water-line corrosion processes in natural and artificial seawater: The role of microbes. Electrochem. Commun., 80: 9-15.

Yeom, H., C. Lockhart, R. Mariani, P. Xu and K. Sridharan, 2018. Evaluation of steam corrosion and water quenching behavior of zirconium-silicide coated LWR fuel claddings. J. Nuclear Mater., 499: 256-267. 